\title{
The Dementia Village: Between Community and Society
}

\author{
Tobias Haeusermann
}

\section{Introduction}

The modern diagnosis of dementia has come to correspond with a number of connotations associated with old age: madness, incapacitation and psychological and social death. ${ }^{1}$ Most people have heard of dementia, as basic disease facts and the factors that supposedly trigger or prevent it have been widely reported for decades, either reliably quoted or flagrantly misquoted. In biomedical terms, dementia is not a disease, but a syndrome produced in large part by diseases such as Alzheimer's, Parkinson's and vascular disease, to name merely a few (Haeusermann 2017). It is a cluster of symptoms and signs linked to the deterioration of cognitive abilities as a person ages. The word itself stems from the Latin demens, for "mad"—or, more accurately, "de-" + "mind" (mens)—and according to the Diagnostic and Statistical Manual of Mental Disorders IV (DSM-IV),

\footnotetext{
T. Haeusermann $(\bowtie)$

Epidemiology, Biostatistics \& Prevention Institute (EBPI), University of Zürich, Zürich, Switzerland

Department of Sociology, University of Cambridge, Cambridge, UK 
it may be caused or characterised by: "The development of multiple cognitive deficits manifested by both (1) memory impairment ${ }^{2}[\ldots]$ and (2) one or more of the following cognitive disturbances: (a) aphasia, ${ }^{3}$ (b) apraxia, ${ }^{4}$ (c) agnosia, ${ }^{5}$ (d) disturbance in executive functioning" 6 (Weiner and Lipton 2009, p. 47). The term "dementia" thus encapsulates a collection of symptoms resulting from a progressive deterioration of cognitive function that cannot be accounted for by normal ageing and that have an impact on day-to-day activities (Ballard and Bannister 2010).

In their heyday, large-scale nursing homes provided a domestic space for the elderly in cognitive and physical decline. Yet they were dominated by officialdom and adherence to acute care protocols. As many critics have rightly pointed out, ${ }^{7}$ such institutions did not always benefit their residents, especially those suffering from mental conditions. With time, the call for more individualistic and person-centred approaches was heard and new care models emerged. The initiation of a pioneering care facility, the Dutch Hogewey nursing home, strikingly embodies this shift. At its opening in 2009, it was the world's first and only village for residents with dementia. It was touted as a place where people could live and die in a communal setting, stripped of the impersonal hospital feel and clinical smell that most care homes still exude. ${ }^{8}$

The idea that it is more harmonious to live amongst primary groups in old age suggests itself intuitively. The significant media attention and conversations in geriatric circles surrounding the opening of the care villages made this plain. ${ }^{9}$ Even before the popular media had shown interest, the concept caught attention in geriatric research circles. ${ }^{10}$ Over the course of its first years and in response to the heightened media attention and the numerous requests from the geriatric community, the village offered oneday workshops for groups of one to five visitors. In its first years, the home became a Mecca for tour groups from all across the globe, and the home's administration decided to convert this rising public interest into monetary gain. Having heard of the new Dutch dementia village model, a team of employees of the Julius Tönebön Foundation in Hamelin, Germany, was sent to the Netherlands to learn more about the new approach with a view to incorporating their findings into a new project in Hamelin. Between May and December 2014, I conducted ethnographic research in the new German dementia village. This included a four-month period of intensive 
study, during which I lived in Hamelin. I spent nearly every day at the village, observing the typical daily activities and assisting the carers in their care routine. In August of that year, I accompanied the night shift workers for one month in order to gain insight into the village's night-time care activities. In total, I observed approximately 650 hours of care work, which entailed countless conversations with carers, residents and administrators, and attended around 60 handover meetings. ${ }^{11}$

The following paper draws on these experiences. It begins with an introduction to Germany's first dementia village Tönbeön am See, its setting and environment, the village's foundation, as well as the home's care philosophy. Throughout, I connect ethnographic observations with the broader events and developments. What follows is a discussion about the care village concept. I frame this discussion by examining the fundamental ambivalence that is inherent in the creation of a dementia village, situation its modern forms between the competing ideals illustrated by the concepts of Gemeinschaft (community) and Gesellschaft (society). Can these two concepts be combined? To offer some tentative answers, I explore how the notion of dementia manifests itself in real life and in the everyday behaviour of the village's residents, their families and the care takers. ${ }^{12}$ I place dementia care at the centre of my analysis. I explore how dementia is experienced, controlled and managed within a distinct socio-cultural environment, at a distinct historical moment and within a specific body of knowledge available at the time. As such, this work's purpose lies in bringing light to the local dynamics and practices by which people with dementia, their families and their care takers are reciprocally and actively moulded into Germany's first dementia village. On a broader scale, this paper launches a more general discussion on ageing in contemporary society and shows how our representations of dementia and the ensuing care practices are largely determined by the social and cultural context.

\section{The German Village}

Tönebön am See is designed to provide a home for people in cognitive decline. Divided into four self-organised communities, it follows the principle of a manageable life world. The village lies in Hamelin, the 
capital of the district of Hamelin-Pyrmont, with a population of roughly 60,000 . Around 200 kilometres east of the Dutch border and a half hour drive southwest of Hannover in northwest Germany, it is tucked away in hills and acts as a gateway to the neighbouring Weserbergland Mountains. The latter are a popular destination for both hikers and cyclists, though the town attracts most of its tourists thanks to its legendary Pied Piper folk tale. The legend tells a story, partially rooted in fact, that took place in the town during the thirteenth century. The Brothers Grimm brought it into worldwide prominence and it formed the subject of renowned poems by Goethe. ${ }^{13}$ That Germany's first dementia village emerged from the birthplace of the Pied Piper tale is not devoid of irony. ${ }^{14}$ While many tourists enjoy revelling in the thicket of Hamelin's history, it seems to be once again a lack of young persons that concerns the town and Germany as a whole. Yet a new and additional loss is emerging: the loss of mind and memory; and a variety of organisations and agents are offering their help and expertise.

The Julius Tönebön Foundation owns and manages the new dementia village. For over 60 years, the foundation has been active in the care business. They are, by their own valuation (and backed by official and semiofficial comparison services), the regional market leader in the care home sector (Focus 2012). Based on their long-standing experience with dementia sufferers in their main care home, which is also situated in Hamelin and where the care recipients live in 3 residential groups of 18 residents each, it was decided that, ideally, the resident groups should be smaller. Moreover, it was thought that the common areas ought to offer more living space to cater for the residents' needs for intimacy, social proximity and security (Tönebön Stiftung 2016). Having heard of the new Dutch dementia village model, a team of employees was sent to the Netherlands to learn more about the new approach and how they could incorporate their findings into a new project in Hamelin. This resulted in four houses, all decorated in different colours and themes. Surrounded by a fenced-off space for 52 residents in total, the houses were intended to allow residents to feel at home away from their former homes. The home's administration defines the main care duties as caring and catering to the residents' physiological needs with food, drink and adequate housing. Meanwhile, their safety is protected by freedom from threats and 
economic deprivation, whereas their relational needs are met by the sense of belonging and affection offered through friendship, love and social interactions. Moreover, carers are instructed to approach residents with respect and to support their existing abilities. The residents, in turn, are expected to experience appreciation and feel self-esteem. In order to achieve this goal, the staff determine each resident's resources, nurture their remaining skills and look for ways in which each resident can compensate for deficient abilities by intervening individually and keeping in mind the specific situation. In line with these objectives, the residents' psychological and emotional needs take priority over physical care. ${ }^{15}$

\section{Coming Home}

I first found my way to the home on a hot and humid summer day. The home is difficult to reach by public transport. A bus stop is planned close by, but for now, a car is the primary and most sensible means of transport for visitors and staff. Some staff members who live in the vicinity, I later learned, cycle to work if the weather allows for it. I had thus decided to walk and was running late, as I had got lost in one of the many labyrinthine allotment gardens of Hamelin's outskirts. I frantically asked for directions, though no one I encountered could point me to the home. "A brain is a terrible thing to watch waste away", uttered a middle-aged woman, while clearing her neatly trimmed flower garden of weeds. "Good luck with your work, it is important to find a cure". Without a compass and a map, but thankfully able to speak the local language, I could only imagine the disorientation in time and place experienced by some residents every day. It could lead to a sense of panic, even eased by the certainty that it will pass. After a few detours through a web of footpaths, it did pass and I eventually stumbled upon the recently completed construction site. So new were its buildings that I could still smell the polished wood.

As I passed the entrance area and what turned out to be the home manager's office, I walked up to the reception desk, which was staffed by a receptionist. She was chatting amicably with a person who seemed to be a resident's family member. To my left I saw a café and a small supermarket. 
The latter has been deemed an integral part of the dementia village concept, as it allows for a touch of normality. The supermarket is meant to distract from the clinical and cold ambiance commonly found in other care homes. Staffed by the receptionist, it is primarily open for residents who come accompanied with a carer. No money ever changes hands; the range of goods is limited to the residents' everyday dietary needs and some basic toiletries. Meanwhile, the café welcomes residents and guests alike. It offers a cosy retreat overseeing and giving access to the sensory garden, and, on occasion, is used for events and festivals. "Hello, Doctor Häusermann, we have been expecting you", the receptionist said. I greeted her and proceeded to inform her that I was not a doctor. The incident reminded me of the widely held German belief in authority and hierarchy. With half of my sentence still stuck deep within me, a resident scurried by and left the building. "Oh, would you mind running after Mrs Weber ${ }^{16}$ and telling her to come back inside?" the receptionist asked calmly but sternly.

I ran after Mrs Weber and barely managed to catch up with her. Once I did, she finally came to a stop. She now stood in the parking area looking all around her, perplexed. Oblivious to my presence, she quietly mumbled some words to herself. I tentatively approached her, tapping her shoulder and introducing myself. She looked at me with tears in her eyes. With a soft and strained voice, she informed me that she was on her way home. I tried to convince her to walk back with me. While I spoke, she squinted her eyes, as though she were trying to decipher what I was saying. Then there was silence. Undoubtedly, I was having my first encounter with the slippery sense of truth in a world that, according to the media's imagination, produces a feigned reality. Steeped in yearning and in a dizzying and disorientated tone, Mrs Weber informed me that she was meant to meet her daughter for dinner and was already running late. She walked another couple of steps towards the cars, wistfully looking around as though she were selecting her vehicle of choice. I told her that dinner would be in the home tonight, which was true. But I lied when I was asked if I would call her daughter to let her know about the change of plans. "Do you know my daughter?", she asked gingerly. I said I did and would call her. She gave me a fleeting smile through her tears but did not seem fully convinced. I felt her determination. After repeating, 
"Let's go back inside where it's not as hot", I gave her a squeeze on her arm, after which she reluctantly followed me back inside. As I stood with her in front of the reception desk, elbow-to-elbow, she looked at me with a lively face. "Thank you!" she said and, in a perfectly coherent sentence, added, "It's nice to see that some still pay tribute to the old-fashioned virtues of hard work". Then she wandered off and soon faded into the distance in one of the brightly lit corridors. In the coming weeks and months, I would spend several moments trying to convince Mrs Weber not to leave the building.

The receptionist thanked me for my help and escorted me to one of the meeting rooms, where I was to be joined by the home's head of care for an introductory talk. She explained that I was now in the main building. The main building boasts function rooms, the main nursing office (internally referred to as the "pool"), and some sanitary facilities for both visitors and employees. The large window front opens to a small garden park with young trees and colourful flowerbeds. The park accommodates a meandering, circular promenade, alongside an aviary and a rabbit hutch. At the heart and centre of the garden, the so-called village square offers benches from which one may witness the water play in a small, electrically operated fountain. Where the park is not marked off by one of the four houses or the main building, some green and a fence keep the residents safe. I would later learn that the entrance to the garden is designed in a way that invites residents to go for a spin. This is to ensure that residents with orientation difficulties cannot leave the terrain without proper guidance. To mirror a German village structure, two of the four houses are detached. In order to reach them, one needs to cross the park.

Matt, the head of care, entered the room. He was in his early 40s, slender, with a strong jaw. Personable yet controlled in his demeanour, he appeared to be hands-on, pragmatic and continuously on the run. Indeed, this morning it seemed as though he held the home together with little more than his phone and his calm disposition. The phone was ringing every few minutes, so he needed to leave our meeting quite regularly. When he returned, he would apologise for the disruption, whereupon he would continue to tell me about the home and that he had only recently joined the team. When we spoke, he was welcoming and sincere. $\mathrm{He}$ promptly revealed in no uncertain terms that he was not interested in 
portraying the project in only a good light, but also aimed to show me "what is really going on". On the day of our initial meeting, he was unhappy with how disorganised the home was. When I began my fieldwork, 27 residents had already moved in, amounting to half of the home's capacity.

Matt's new post was tailored to his strengths and attuned to his career trajectory:

I'm coming from another home, and was ready for this challenge. There's so much right with this home's visions and yet still so much wrong with how we're doing things. Right now we can't provide the quality here that I had initiated in the former home I worked at. But it's hard. The foundation wants to break even and doesn't give us the staff we need.

He spoke in a conversational tone, obviously aware of everything there was still to do. "I know that you're coming from the Netherlands", he continued. "Hogewey is a great project, but they have so many more financial resources at their disposal; something like that is not possible in Germany, despite our best intentions". While he was happy with the initial concept of the home, he articulated many enhancements that needed to be addressed. He then offered to show me around.

\section{The Brickyard Mansion}

We stepped into the first of four houses, the Villa Ziegelhof ("Brickyard Mansion"). The interior was designed in a modern and contemporary style, with brightly coloured walls. Matt then took me to one of the unoccupied rooms, the "showroom", as they call it. It was spacious and, aside from one bed, there was no furniture. Matt explained: "The residents ought to bring their own furniture, in order to feel at home, that's important, you know, so they have some memorabilia. When residents move in, it leaves a void, and familiar surroundings need to fill it”. The bathrooms were generous and finished from floor to ceiling with white tiles, which gave them a slightly clinical feel. They were easily accessible by wheelchair and the floors were evenly levelled. The shower was in the 
corner, and no doors obstructed access. All the amenities were state-ofthe-art. "Do you lock the doors at night?" I asked. "No, we don't", he responded, continuing:

You know, I believe that if we succeed in sheltering the residents from all danger, we will have failed as carers. This should not be a golden cage. It's interesting, the relatives would rather have us increase security and lock the individual doors at night. At the same time, the social romantics criticise us for having the village fenced off, so one's mother or father can't 'run there'.

I asked why he said "run there" as opposed to "run off", to which he replied: "We say danger of 'running to' [Hinlaufgefahr], not 'running off' [Weglaufgefahr], because for the residents, they don't feel that they are running away. They are going somewhere, they want to go home, or shopping, or whatever. So they are not running away". He continued to tell me about an event that had occurred recently:

Two weeks ago we had one resident disappear. The two carers on the night shift called me. It was the weekend. They had looked everywhere, but they didn't find her. So they called me in the middle of the night and we eventually had to call the police, and they came with a helicopter. We looked everywhere in the surrounding woods. It was late at night. Eventually we found the resident in the closet of an empty room, anxious and distraught. We were lucky to find her inside the village. But you see, when you're dealing with such cases, hearing people's criticism of the fences becomes laughable. Obviously it would be nice to live in a free and happy environment, but if something happens to a resident, if they get lost, or if they drown in the lake, who will be held responsible? The same voices will ask: 'Why didn't anybody stop her?' Sometimes the dementia discourse is packed with hypocrisy.

In order for the residents to "feel" free and remain safe, the dementia village needs to draw clear boundaries. Where are the fences? How high can they be? Which doors should be locked? Which rooms ought to be accessible? How much hygiene is needed? The extent of freedom is highly negotiated between concerns for safety and freedom. On our way to the second house, we strolled by a couple sitting on the porch. I was about to 
introduce myself but immediately sensed the weight of the moment we were walking into. The wife was a new resident. Ever since she had moved to the village, her husband would dutifully visit her every day, generally in the afternoon. They were sitting next to each other on two wooden lawn chairs. The wife was fighting back tears. We caught snippets of the conversation: "and you always told me, no, no, you'll be back, don't worry", she said. Her husband spoke thoughtfully and deliberately, "Yes, that's what I said". The wife's voice started trembling and cracking: "And I told you that I don't want that. You don't need to care for me; I'm perfectly capable of taking care of myself. Once I go back to school, and my house, then I'm happy. You might as well have thrown me into the Weser [the local river]".

The husband looked at us, as though searching for comfort and reassurance. He then replied with casual interest, "I told you again and again, you can't come home". The wife noticed our presence and managed a tight-lipped smile. But her breathing was rapid and her face flushed with turmoil. Matt raised an eyebrow and answered his phone. We then walked across the square in the centre of the village, past the village fountain. On our way, Matt told me that the wife had repeatedly locked out her husband and called the police, whereupon her two sons and husband had decided to bring her to the home. Additionally, she suffered from Hepatitis C, which made caring for her difficult, as one constantly needed to be cautious not to get infected. "It's hard to move to a new place at this age. With emigration comes loss and then grieving". Matt let this hang in the air for a moment, then continued:

You surely know Elisabth Kübler-Ross' (1969) work. In her five stages of grief, the first is denial. In the beginning, many residents deny that they have actually left. But as the days tick by, the permanence of the move will sink in. But this is a journey they need to take together with their loved ones. And we need the families to be involved.

Indeed, the home's management deems the families' involvement an important element in the care routine. "The fates of family members and residents", an internal care document states, "are inextricably linked". For this reason, besides their daily nursing duties, the staff are responsible for 
offering family members information, guidance and clarification with regard to their relatives in the home. Family members and caregivers are advised to be in close contact to understand and support each other effectively. According to the village's administration, this is achieved through several means. First, and prior to their relative's entry, the families receive information about the particular services offered in the housing communities. Second, they are asked for biographical information and memorabilia that might make it easier for the relative to settle in and feel at home in the new environment. Third, the family ideally provides comprehensive information on the relative's possible behavioural problems, their background, their household routines and potential issues that may arise. Fourth, the families are encouraged to be involved in everyday nursing routines and the care design. Should a resident be dissatisfied, their family will be approached early and it will be stressed that all criticism will be perceived as an incentive to improve care and not as a personal attack. This is ideally facilitated through regular family events and a dialogue with the carers.

\section{The Lakeside Mansion}

We moved to the next house, the Villa am See ("Lakeside Mansion"), the décor of which, according to the prospectus, was classic and timeless. The walls were painted in warm red and brown colours. Here, all residents had already moved in. The houses were connected through a glass hallway, something Matt was not happy about. "The initial idea really was that the houses stand individually and not connected, but well, we haven't fully managed to have this materialised. Safety and comfort had to come first". We walked through the sitting room, past a TV area with a giant state-of-the-art television, several sofas, and a bookcase filled with the works of many famous poets and authors, fairy tales and children's books. On the bottom shelf, I saw various board games and play materials - the sort one finds in typical German households, ranging from Mensch Ärgere Dich Nicht (Ludo), checkers and playing cards to a myriad of colourful jigsaw puzzles and two large foam dice.

Most of the residents had already eaten and were either relaxing in their rooms or taking a rest on the sun terrace. On the terrace, six women 
were sitting around a wooden table, serenely drinking coffee and water and looking out upon the neat flower beds and the village's pastoral peace. To protect the residents from the harsh, unyielding sunlight, a dark blue parasol had been stretched to cover. The ladies sat in silence with a seeming calmness about their twilight years. Every now and then one would utter a brief comment, either about a carer passing by, the heat or the bees and flies that kept settling upon every brightly coloured piece of clothing. In the background, one could hear the gardener mowing the terraced lawn behind the building; a smell of freshly cut grass and petrol from the mower lingered in the air. Beside the table, several wheeled walkers were parked together. An elegantly dressed woman in her early 60s, with bleached blond teased hair, was trying to cut through the convoluted line of walkers. She wanted to retire to her room and shot us a nervous glance. Matt tended to her well-being and wished her a good rest. Then a primlooking carer walked out of the house, carrying more glasses. "Let's make sure we all drink lots of water, we need it in this heat", she said cheerfully, while pouring glasses of water for everyone.

\section{The Ridingyard Mansion}

We returned inside the house and walked down a bright, glass façade corridor that connected the Villa am See with the third mansion, the Villa Reithof ("Ridingyard Mansion"). This third edifice overlooked the horse stables next door. The stables formed a striking contrast to the newly built care village. The grass needed cutting, the roof patching, and quite a few surfaces warranted a fresh coat of paint. The décor of the mansion was in the style of a country home. Matt then led me into the dining area, which was separated from the kitchen by a countertop, cluttered with leftovers from lunch. A feisty young carer with long dark hair was brushing off bits of salad and pasta from dishes and utensils before loading them into the dishwasher. Eight tables with chairs were arranged alongside the window front. Meanwhile, two residents were finishing their desserts in the dining area. One resident was singing the same verse of an old German children's song. Every now and then the carer would sing along with the 
resident by starting a new verse. The singing resident then made a violent lunge for her table neighbour's spoon and began tapping on the wooden table. By the look on her neighbour's face, this created an unsettling sound. The neighbour then stood up, rambled a bit, and dashed off to her room. Nearer to the carer, another resident was casually leaning against the counter, overlooking the kitchen. There seemed to be a warm quiet between the two. The carer would steal cheeky glances at the resident, and the resident would smile back. Yet due to the neighbouring horses and the summer heat, the carers struggled to cope with the flies sneaking into the house. One carer, folding clothes, was frantically killing the insects with a fly swatter. "This is the home I'd prefer for myself", Matt declared. "You see the horses from the window, so there's always something going on".

The home's care philosophy posits that the staff see the residents' behavioural syndromes as expressions of self-help, self-preservation and self-protection. Their actions are understood as a response to the feeling of loss that the residents experience. Also, any abnormal behaviour from a resident is appreciated as the resident's way of adjusting to their new realities and compensating for their shortfall in other communicative means. In that vein, challenging behaviour is recognised as a self-healing attempt in response to physical, mental or social wounds incurred as a result of the disease. The behaviour is thus not perceived as a deficit, but triggered by the deeply painful losses and interventions in the residents' lives.

Consequently, the carers are encouraged to see challenging behavioural manifestations as residents' subjective and meaningful engagement with their own bereavement. Instead of surpassing the symptoms of such selfhelp attempts, the carers are meant to connect with each resident, to discuss, and to strive to understand the individual's loss. Reportedly, there is a wide range of behavioural symptoms. While the residents frequently undergo a personality change, their emotional feeling (it is stressed) is not clouded and their ability to direct attention to external stimuli remains. With this understanding of behavioural problems in mind, the carers are believed to be more successful in empathising with the residents. For the latter, the experience of distance and proximity is 
sometimes skewed. While potentially incomprehensible to an outsider, residents often seek close body contact to get attention, to make themselves heard, or to deal with stressful circumstances. Furthermore, fear and distrust - and even hallucinations or delusions-may occur and unpremeditated, new or unpleasant situations such as a visit to the hairdressers or the doctor may cause fear and distress. Internal tensions and torment can lead to excessive motor activity, even agitation. Restlessness and confusion may increase in the evenings, which is referred to as "sun downing" and is often accompanied by a strong inclination to run away, or, in adapted care speech, to "run to". Conversely, a lack of drive and motivation can occur, paired with a higher perception and expression of pain. Lastly, feelings of hunger and thirst generally decrease, and, sooner or later, the residents ordinarily become incontinent.

\section{The Hastebach Mansion}

The last house we visited was the Villa Hastebach ("Hasty Brook Mansion"), which was named after the small stream meandering through the countryside not far from the house. With blue and white walls, giving it a Nordic Scandinavian feel, the mansion was still uninhabited. Some carers had cut out a few paper fish for decoration, some of which were already dangling from the roof. Next door, the former brickyard was being rebuilt into a day-care centre. "The idea is that the residents will be able to join some of their activities once it's finished", Matt declared. "This ought to offer them some more activities, while at the same time relieve the carers in the village. In general, there is no forced sociability". He continued: "If residents want to spend the evening with other residents, it should be because they really want to".

After taking a slight detour around the ward, we once again crossed the village square to return to Matt's office. On our way we encountered another resident. She was sitting in one of the flowerbeds, engrossed in playing with some stones, watching the dirt slip through her fingers. As we passed, she noticed us. She stood up, gingerly brushing the dirt off 
her trousers and moving a strand of her silver hair out of her face. With one foot bare and the other wearing a wet sock, she stood rooted to the spot. Her tan highlighted her finely chiselled features, emphasising the magnetic quality of her clear green eyes. Matt introduced me to her, mentioning that she had previously been a yoga teacher. She gave me an amicable smile. With a natural dignity and presence, she reached out her hand and placed it on my arm. "How wonderful to finally meet you", she said enthusiastically. "It's quite warm, isn't it. Yes, it is indeed. And the flowers are just blooming like there's no tomorrow, it's just marvellous". I agreed and asked her if the hot weather was not bothering her. She looked at the sky, then away from it and back at it again. She then shut her eyes as though she were squeezing out a thought. She pointed at some tiny clouds in the sky and said, "I see it coming already, you know, these big, big, you know... you never know what's going to happen, life is full of surprises, isn't it?" I asked her if she enjoyed living in the home. She replied: "Oh, there's always a little of this and that. You never stop learning, isn't that so? And this here [pointing to the bush behind her], it's quite remarkable, quite remarkable I tell you. But I think I had better get back to work now". We said goodbye and she returned to her spot and resumed digging up stones. Mrs Edwards, Matt informed me, had been brought to the home by her son, a famous heart surgeon from the north of Germany. She had gone missing for several days in the city before someone eventually discovered her in a garden shed. What was remarkable about our conversation was that Mrs Edwards seemed to formulate well thought-out and coherent sentences, at normal volume and speed and with a conversational tone. Her speech was nevertheless detached from reality and context, just as her behaviour and attire did not really match the conduct normally associated with that of an elderly, elegant woman. "In a regular nursing home, Mrs Edwards probably wouldn't be allowed to dress like that or play with dirt", Matt told me while we walked back to his office. "But we don't presume to know what she wants and enjoys, we provide a safe, familiar and human environment, so she can do what she enjoys. They don't come here to die, but to live". 


\section{Discussion}

When the village was inaugurated in March 2014, the project's chief administrator did not mince her words: "Here we see how care work works in the 21 st century. This is a great project for Hamelin, it is a great day for the city". And the chairwoman of the Tönebön foundation added, with reference to the village's critics, that the residents should not be seen as having been "deported" or "marginalised", as they would continue to partake in Hamelin's social life. "We want to make their daily routine as normal as possible", she emphasised, maintaining that what and where they eat is up to the residents themselves. "The refrigerator door is open to anyone, anytime. If someone wants to make coffee in the morning or eat a yoghurt, they can". The village is a primary example of "full inpatient care where the residents remain self-determined", which is "very labour intensive" (Keller 2014). ${ }^{17}$

The home had two advantages when it opened its doors. First, it could model its design and principles on the successfully implemented Dutch care home, learning from the Dutch experience and continuing the tried and tested approach. This circumstance proved vital in convincing investors and critics. Second, the model's novelty and progressive methods invited not only many families and individuals from around Germany to consider it as a potential care home, but equally grabbed the interest of many carers. ${ }^{18} \mathrm{~A}$ few weeks after the inaugural celebrations, when I first visited, the village was still in turmoil. Undertaking a new project and implementing new processes is always a bumpy road, and launching the first German dementia village proved no exception. When I began my fieldwork, the care staff comprised 18 team members ( 15 women, 3 men), and the residents occupied two of the four houses, with more residents moving in every day. Management did not know how much staff was needed, who exactly would move in, or how things would work in detail. The residents had been uprooted from their former lives, the new workers needed to acclimatise to their new environment, and all of this occurred in the presence of much uncertainty. In between the intricate rules and philosophies laid out in the village's blueprint, and the frantic everyday care routine, there often was not much space for contemplation. Before we thus venture deeper into the everyday care routine, it is worthwhile to bring more attention to the idea of a dementia village. 


\section{Gemeinschaft und Gesellschaft (Community and Society)}

The dementia village, by its very concept and application, creates a new demarcated space for its residents governed by societal standards of care. The residents live in the community. The carers, on the other hand, fulfil a societal function. They come in from outside to work, but do not live with the residents. This distinction between the two concepts-community on the one hand and society on the other-ties into a long-standing tradition in social thought that speaks to the tension of combining sociality with rationalised bureaucratic efficiency. Ferdinand Tönnies (2001) distinguished this as a tension between Gemeinschaft and Gesellschaft.

The concepts of Gemeinschaft and Gesellschaft, Tönnies (2001, pp. 27 f.; p. 254) argued, form the ideal types of social organisation. Gemeinschaft represents the communal society, in which personal relationships are structured based on time-honoured social rules. Tönnies differentiated between three original types of community, bound together by blood, proximity or conscious thought, which he referred to as kinship, neighbourhood and friendship/comradeship. Each of these forms of community is defined by a specific set of roles and a distinct awareness of the place each person occupies in the group. The members' worth and status stems from knowing who they are, where they come from and where they belong. Their worth is not tied to their achievements. This, however, also implies immobility, in both physical and social terms. Members commonly stay in one place and remain in their hierarchical positions. What follows is that a community is, by its very nature, exclusive. People outside the community may be welcomed as guests or workers who provide services on a temporary or permanent basis. They might even, with time and commitment, become passive members. Yet they hardly ever take on the role of a representative. Exclusion, not inclusion, characterises the communal spirit. While solidarity is at its core, it is also the core of a clearly defined circle, the borders of which are difficult to cross.

In contrast to the concept of community, Tönnies' notion of Gesellschaft embodies an association that is regulated by modern, multicultural societies with their governmental bureaucracies and sizable institutions. Society comprises individuals who may coexist peacefully but are, in essence, substantially separated. In this manner, it is every man for him- 
self, living in a perpetual state of tension. The union is characterised by reciprocity, wherein for every service rendered and good provided, a return is not only expected but legally and socially required. In these social relations, roles are soluble and fluid, and individuals are detached from one another and become separate selves in the same way that deeds and goods become separate entities. "In Gemeinschaft", Tönnies (2001, p. 52) writes, "[people] stay together in spite of everything that separates them, in Gesellschaft they remain separate in spite of everything that unites them" ${ }^{19}$

In the dementia village, there is a contrast between the residents and the carers as of the village. The reality of living in a specially designed village is that it makes reality feel just that little bit less real at times. Whereas the home was designed to be a "village" in which carers would cook with patients, do laundry with them, and so on-a village in which everything would resemble civic life-there is evidently a division into groups. Most prominently, residents and carers do not form part of a community existing side by side, but have very different interests and roles. For the carers, it is a job, but also a calling. And the residents form, similar to any other "village", an inherently diverse and dynamic group. Some are happy and thankful, others are aggressive, hitting and punching the carers, and others are sad and depressed. If you take a group of people and put them in a village, naturally you will find quite a wide variety of hobbies, sleep patterns, food preferences and so on. To build a community in Tönnies' truest sense of Gemeinschaft, a care village, one could argue, ought to evolve internally; it should not be an organisation representing a form of Gesellschaft, driven by a single overbearing vision.

When thinking about the dementia village, we thus need to reflect on the often unasked and unanswered questions with which we need to reckon in a discourse about dementia care. As we have seen, several key themes ran through the media reports on the village, and the idea of a dementia village seemed to take on a life of its own. A tenaciously repeated opinion posited the concept of normality as the foundation of the care village. But what is normality? And if we need a care home to feign it, what is wrong with normality outside the confines of an institution? The principle of normality is, of course, an entirely subjective matter and defining it involves a normative, culturally informed choice. In order to 
exist within an institution, the care home must necessarily dictate how normality ought to be experienced and lived, because otherwise order and safety could be threatened. If one resident's idea of normality includes singing at midnight, another's normal sleep pattern might be disturbed. The recourse to normality thus entails a moral and even political evaluation by which the cohabitation form is mediated. For this reason, the concept of normality is, in each instance, a debatable principle. ${ }^{20}$

One of the striking differences between the German and Dutch model concerns the idea of community building within the village-or how normality is conceived. The Dutch village created different life worlds for their residents, wherein the residents' backgrounds and former habits formed the basis of their cohabitation groups. In Germany, this approach was not adopted. On the contrary, the idea was rejected-possibly due to the nation's very sensitive history with segregation and the idea of health care being distributed equally. The shared commonality of the residents, besides the fact that they were all German citizens, was their need for care. One of the project's initiators phrased it as follows:

Whereas in Amsterdam the houses are divided amongst different groups of patients, according to their hobbies and origins, we didn't copy this aspect of their model. Here we have rural communities, people share similar origins, and their houses are not divided. You may find a former sales assistant, a teacher, and, yes, even a professor might move in. And we didn't differentiate between those groups.

Another carer was a bit more blunt, saying: "Can you imagine? Separating people based on background in Germany? We might as well call it the Third Reich village!" An administrator, in turn, stressed that there is no singular admission criterion that exhausts the possibilities of the concept. Rather, the village concept should always be situated within particular contexts:

If we had followed the idea of the dementia village to the letter, this would beg the question of how demented you need to be to be admitted to the village. And I know of families who'd rather take their mother or father to a local care home that does not specialise in dementia, as otherwise everyone would immediately think she is mad. So there is still a lot of educa- 
tional work ahead in order for the condition not be as disreputable. I think that whether you physically or mentally depend on care, there shouldn't be a difference.

These social differences could lead to friction with those residents who did not feel at home amongst the other residents. The exclusionary principle of the Dutch dementia village collided with the German understanding of equal health care provision. Certainly, the initiators of Hamelin's dementia village never strived to create an exact replica of the Dutch dementia village. They explicitly adopted a "mix and match" strategy for the project, to the extent that the carers often yearned for more structure than the model was initially designed for-a structure that would categorise residents according to the degree of their dementia progression in order for them to fulfil their professional duties better. The differences in the way in which the Dutch and German dementia villages conceived and delivered their care services does not mean that one approach is right and the other is wrong, or that one necessarily offers more person-centred or individual care. It only means that they are different, and that certain socio-cultural values inherent in the existing arrangements probably come into play.

By its very nature, an ethnographic account cannot demonstrate either the generalisability or predictive power claimed by other scientific disciplines, which tend to approximate such ideals more closely than ethnography can, ever will and indeed should. Then again, ethnography derives its efficacy in no small measure from the insight that there are limits to our interpretations. It builds its strength by knowing its boundaries. This paper does therefore not depict an entire country or culture or a token programme representing Germany in a strong and distinctive fashion on a macro level. While it is vital to allow for both cultural and environmental factors (Jacobson 1991), we should refrain from artificially establishing national binaries. ${ }^{21}$ Nevertheless, by pointing out the difference between the Dutch and German model, we can see how they both grew from deep historical and ideological roots. The same is the case with Tönnies' conception of Gemeinschaft. Whereas his evaluation is structured around a sequence of conceptual dualistic contraries-or what he called "normal types" - they are not merely abstract analytical tools. ${ }^{22}$ In 
Tönnies' (2001, p. 17) view, social relations may be understood either as originating from genuine, natural bonds, which are the heart and soul of communities, or as an essentially mechanistic formation, steeped in reason and thought, which is what we conceive of as a society. This differentiation evidently implies certain judgements. Indeed, Tönnies framed his normal types with the underlying notion that naturally evolved social relationships in the community are favourable. By contrast, artificial and systematic relations in society are "predatory and pathological, a distinction that [bears] all the hallmarks, not of the 'mechanistic' outlook of the scientific enlightenment, but of Aristotelian and medieval scholastic roots" (2001, p. xxvii). The straightforward division between community and society does not conceal the circumstance that defining and using a community as an empirical field of study is a tricky and controversial task. "In considering the concept of community", Colin Bell and Howard Newby (1971, p. 2) maintain, "the sociologist shares an occupational hazard with the architect and the planner; the more he attempts to define it in his own terms, the more elusive does the essence of it seem to escape him". Too often, subjective value judgments colour the description of a community, and the mere definition of a group as a community mightand indeed often does-involve one's normative recommendation of what it should be. ${ }^{23}$ Just as the conceptual notion of "contract" dominated the intellectual discourse throughout the Age of Reason, "community" occupied a powerful position in the attitudes of nineteenth century sociological thinkers. The concept was not merely a callous, methodical instrument for reaching an empirical description of social relationships. Rather, the term accompanied an undercurrent of positive and nostalgic associations, to the extent that the move from close personal and communal bonds to the contractual, utilitarian and impersonal relations found in an emerging industrial society was often lamented (Bell and Newby 1971).

Comte, for instance, held that Western states had emerged out of political and industrial revolutions and were abnormal and artificial fabrications, both dangerous and lacking emotional and social competence. He feared that modern-day authorities were negligent in taking care of their population. In view of the vast diversity in the populace and to regain a sense of community and connection, he suggested that modern 
states be broken down into smaller units, comprising cities, towns and their surrounding countryside (Pickering 2009). In Suicide, Emile Durkheim (1897) expressed concern that the decay of collective conscience and the deterministic shift to individualism was causing the fall of long-established communities. This could lead to what he termed "anomie", or a complete and utter loss of societal norms. Yet, as opposed to Comte, he believed that the rising division of labour would, while destroying traditional communal ties, lead to the formation of new and bigger organic communities, as different types of solidarity would emerge.

Lastly, Karl Marx's use of the term "community" exemplifies the contrast in usage that pervades the above thinkers' accounts. On the one hand, Marx held a more descriptive sense of the concept and saw community as a group of people living together as a collective and sharing various historical, social and economic ties. These primitive communities, which he refers to as "natural communities", stand in contrast to the feudal community that, for centuries, formed the backbone of medieval European society. On the other hand, Marx held a normative prescription of community, which he would sometimes term "the real community". This represented Marx's notion of freedom, wherein one does not depend on the servitude of others (Brenkert 1983). Tönnies indeed demonstrated his affinity to many Marxian notions of capitalism throughout his work and applied several elements of Marx's ideas to his conceptual framework. Ultimately, however, he understood the emergence of a tradeheavy capitalistic society not so much as a cause for the demise of community, but turned Marx's thesis around and argued for a structural explanation. In this fashion, he claimed that the loss of communal life provided a fertile ground for the growth of new social organisations (Cahnman 1973). Irrespective of their diverse approaches, all these accounts share a certain praise and positive regard for community. They see in it "man's natural habitat" (Bell and Newby 1971, p. 22), endangered by the faceless, impersonal and anonymous industrial society. A strong sense of nostalgia and an unsettling sense of placelessness accompany most thinkers' images of fading communal life. In the words of Keith Melville (1972, p. 171), however:

The danger of any form of nostalgia is that it is so simple to imagine a past which never existed. It is seductively easy to assume that, until the 
beginning of the industrial age, community universally mean that one was always close to the warm bosom of cherished friends and welcome traditions.

Tönnies' theory provides a simplistic notion of community and society. Implementing one automatically rules out the other. In the real historical world, however, the two types coexist; the boundaries are permeable. The dementia village presents a case in point. For that reason, it is not a question of whether individuals and organisations, in their thoughts and actions, form exclusively a Gemeinschaft or Gesellschaft. Rather, the question is where on the spectrum between these two poles the object of enquiry is located (Tönnies 2001, p. xxviii). We must bear this in mind when further exploring the village's notions of community and society. While it is tempting to recognise the two concepts as physical, tangible bodies, the very character of a social group does not lie in its biological or geographical qualities but in the inherent relational connections that bind the group together. ${ }^{24}$

\section{Conclusion}

"A brain is a terrible thing to watch waste away", uttered the amateur gardener of the labyrinthine allotment gardens when I asked her for directions to the new dementia village. Her remark called up an image of a rotting brain that had once ripened. As some accounts in this paper have illustrated, however, life in a dementia care home can be much better than what is suggested in some of the mortifying clinical portrayals. Questions addressing appropriate and novel ideas for dementia care, however, also resonate in utopian and theoretical accounts of community, of which the dementia village is an example. The longing for more inclusive, collective care models that emphasise human relationships and solidarity rather than calculated self-interest is found in many care circles. It is felt as profoundly as the discontent with the diminishing bonds of kinship and family seen in nineteenth century thought. Yet the universality of home-or, in this particular case, "the village" as a place for careleads us to comprehend it as both undisputed and natural, and we tend to neglect or underrate the ways in which it is culturally determined. 
Such ideas are strengthened by the common yet precarious view of home and community as the "natural" place of care and effortless relationships that are bound by emotions and connection, while medicine and cure carry the connotation of knowledge and comprehension of facts. The dementia village project evolved amongst many human and touching experiences, thankful relatives, husbands visiting their wives every day and a strong team spirit and cohesion amongst the carers. ${ }^{25}$ The home, designed to be a village in which everything resembles civic life, might not have met this vision, but it did not lack humanity. It did not lack care. Neither did I encounter insufficient or bad care. The carers did care, and most of them with sensitivity, rather than sentimentality. Nonetheless, the rising prevalence of chronic illnesses means that care is becoming an increasingly complex affair. It is with due regard for these actualities that we must construe the relationships between the village residents, the carers, dementia and social life. And I hope that by outlining some of these complexities, this paper will foster a deeper and more critical understanding of dementia, ageing and the care we all hope to receive in our twilight years.

\section{Notes}

1. In the mid-1960s, social psychologist Richard Kalish (1966) introduced the notion of "psychological death", referring to a demise of consciousness resulting in the individual ceasing to be aware of their own self. Thus, the individual not only forgets who they are but also that they are. Arthur Kleinman (1988), in turn, forcefully argued that language and social exclusion, consciously or unconsciously, can lead to a descent into a passive solitude, which literally engenders "social death" (also see George 2010).

2. The impaired ability to both learn new information (working memory) and recall previously learned information (long-term memory) (Weiner and Lipton 2009, p. 47).

3. Language disturbance (Weiner and Lipton 2009, p. 47).

4. The inability to carry out motor activities in spite of intact motor function (e.g. strength and coordination) (Weiner and Lipton 2009, p. 47).

5. A failure to either recognise or identify objects in spite of intact sensory function (Weiner and Lipton 2009, p. 47). 
6. For instance, planning, organising, sequencing or abstracting (Weiner and Lipton 2009, p. 47).

7. See, for instance, Townsend 1952; Goffman 1961; Foucault 1989 (1963); Zola 1972; Rosenhan 1973; Smith 1974; Noddings 1984; Gubrium 1986; or Weinberg 2005.

8. Branded as an innovative, humane and affordable model of dementia care, the village today hosts around 150 residents, averaging 83 years of age. Roughly 250 full- and part-time health care workers and local volunteers care for the residents. The residents live in 23 different homes, each catering for 6 or 7 residents. These are categorised in seven diverse "lifestyle categories", which entail housing for the Dutch upper class, homemakers, trade/craftsmen and women as well as religious, cultured, Indonesian (for those who most value their ethnic heritage) or urban residents. Two core principles govern the village. First, the village strives to give residents a home in which they are surrounded by recognisable objects and people with similar values, backgrounds and interests, in order to create experiences that are reminiscent of the resident's formative years. Second, much emphasis is placed on keeping the residents active and in a safe environment. Twenty-five clubs offer activities that include folksong, bingo, painting, cycling, literature and baking (Zorggroep (2016); Berry 2013; Carpenter (2012); Henley 2012; Tagliabue 2012).

9. See, for instance, Grün 1998; Hurley 2012; Jenkins and Smythe 2013; or Hogewoning-van der Vossen 2004.

10. In Switzerland, a care centre in the form of a mock-1950s is currently under construction, intended to cater exclusively to elderly residents with Alzheimer's and other dementias (Grogg 2014; Paterson 2012). In the UK, a replica village high street was recently built at a dementia care home in Suffolk to help the residents retrieve some of their memories (BBC 2014). Also see Keller (2013) for other German projects.

11. The 650 hours correspond with the carers' work schedule. I generally conducted participant observations during entire work shifts. Nightshifts would usually last up to 11 hours, whereas dayshifts spanned over a period of 8 hours. I did not explicitly call the interviews such; they were often down-to-earth chats peppered with banter, confessions and life stories. As the later chapters will illustrate, they were far from formal. They took place in between and on the way, over coffee and during cigarette breaks, on benches and table chairs and while peeling potatoes or washing up, brushing someone's hair, cleaning the floors, consoling a crying resident or chuckling over a joke while pulling support stockings over someone's feet. The open-endedness of ethnography offers this 
much-needed flexibility, making it, in the words of Sarah Franklin and Celia Roberts (2006, p. 93), "radically exploratory". Initially, valuable findings took the form of questions, rather than answers.

12. In order to bring more clarity by way of a culturally informed view of dementia, I took a position-one also adopted by anthropologists Margaret Lock (1993, 2002) and Tsipy Ivry (2010) — that understands knowledge about our bodies and minds as a product of history and culture. When addressing the mythologies of menopause in Japan and North America, Lock (1993, p. 370) pithily concluded that the condition "is neither fact nor universal event but an experience that we must interpret in context". To quote Darin Weinberg (2005, p. 7), "social studies of science have shown time and again that scientific discoveries are temporally situated social constructions rather than revelations of a timeless and uniform natural order". In this view, care practices stem from their "embeddedness" in systems and ideas about health and illness, individuality and selfhood that exist in a "productive network" that permeates the social body in its entirety (Foucault 1980, p. 243).

13. In the English-speaking world, the tale is primarily known for Robert Browning's poem The Pied Piper of Hamelin (Curren et al. 1942).

14. Perhaps the greatest ironic juxtaposition, however, is that Hamelin is also home to Germany's largest juvenile detention centre, which lies less than $1 \mathrm{~km}$ south of the newly built village. Hamelin's youth detention centre provides accommodation for young people between the ages of 14 and 24 who are remanded in custody or sentenced to a period of confinement, of which the average length is 1.7 years. Although it didn't open its doors until 1980, Hamelin's prison history goes back a long way. It dates back to the Thirty Years' War (1618-1648), after which Hamelin was converted into a large country fortress. As such, it served as a prison for the "dangerous subjects of the country". Throughout the following centuries, new buildings were added and the prison was continuously expanded. During the Nazi dictatorship, it was used to detain political prisons, opponents of the regime and homosexuals (40 of whom were violently liquidated in April 1945). In the post-war years, the British government briefly used it as a detention centre for war criminals and added an execution site. Once returned to the federal state of Niedersachsen (in 1950), it was eventually converted into a juvenile detention centre. The 150-year-old prison, however, proved entirely unsuitable as a juvenile prison, which is why a new building was erected in the south of the city (Jugendanstalt Hameln 2015). 
15. The sections discussing the home's care philosophy are primarily based on extensive interviews with the head of care and manager of the village, as well as internal documents and guidelines to which I was given access.

16. To protect her identity and the identities of all other residents and carers discussed in this paper, I have observed the convention of changing the name and defining characteristics.

17. The vision of full in-patient care in which residents remain selfdetermined inaugurates a thematic dimension of this paper-namely, understanding dementia care as a way of managing contradictory and complex demands for safety, health and autonomy.

18. When I began my fieldwork, several hundred carers had already sent in their applications, some frustrated with the bureaucratic and rigid work environments in other establishments, some inspired by the concept's apparent uniqueness, and others displeased with other homes' prevalent tendency to medicate residents.

19. At the time, Tönnies' assertions and theories contested widely held views of German philosophical circles. He challenged the then distinct tendency in late nineteenth century political thought to overly confine itself to the "individualism vs. collectivism" debate. Tönnies claimed that drawing a clear line between the two concepts was a futile endeavour, as both simply embody two separate forms of individualism (Merz-Benz 1991; Walther 1991).

20. Without a doubt, psychological and sociological literature, alone, is replete with examples of discussions of "normality". To name but two: Margaret Lock (2013, p. 42) engages in detail with the biomedical side of dementia research and includes a detailed discussion of the relationship between dementia and normal ageing. Drawing on Michel Foucault and Auguste Comte's work, she writes that "until well into the 19th century use of the term 'normal' was virtually limited to the fields of mathematics and physics. It was not until an internalising approach to the body based on anatomy took hold that arguments about the relationship between normal and abnormal biological states were seriously debated for the first time". In Concepts of Normality: The Autistic and Typical Spectrum (2008), Wendy Lawson, on the other hand, compellingly outlines theories behind the Western conception that has led to a culture that fails to be inclusive.

21. Nevertheless, my research reveals levels of explanation that touch on national or cultural idiosyncrasies in the observed care approach. Such differences include political-economic variances, contrary ideas of 
autonomy and family ethics, and contrasting gendered expectations. Yet, as George Marcus and Dick Cushman (1982, p. 31) note, traditional chapters on "geography, kinship, economics, politics and religion" merely suggest the theoretical stance that societies can be synthetically divided into such analytical elements.

22. Tönnies wrote his influential work at a time when the German empire was striving for national unity, ready to take great leaps forward to achieve their lofty goals. In 1878, when the first edition of Gemeinschaft und Gesellschaft was published, the German election had been won by the Conservatives, while the Liberals and Social Democrats had lost many seats. National unity was not achieved as a result of a republican movement, as had happened in neighbouring France, or as a compromise between the democratic bourgeoisie with the nobility in England. Rather, unity was the result of an imperial alliance of German states under the hegemony of the Prussian nobility. Germany was missing the embourgeoisement that had taken place in England, the Netherlands and America. Seven years before, the young state had won the FrancoGerman War and the resulting tribute payments from France boosted German industry. Meanwhile, with the onset of industrialisation, emerging cries for social change began to undermine the once resilient feudal order, which spurred on a strong and confident labour movement. These new influences found themselves facing the old forces of nobility, the Church and the politically weak bourgeoisie. While Tönnies sympathised with the labour movement, he did not necessarily see his role in advancing the processes fuelled by socialist theory. Rather, he wanted to enhance the civil structures needed to achieve a democratic-republican civility. It was this contract for civility that he attempted to fulfil in his function as a social scientist, and he did so by juxtaposing the social philosophy of the contemporary German Wilhelmism and the historical school of relationalism with its roots in seventeenth century natural law. With imperial Germany lacking a sovereign rationality theory, Tönnies sought his role models in countries where reflections on civility (Hobbes in England and Spinoza in the Netherlands) had prospered more than in his native land (Merz-Benz 1991; Walther 1991).

23. They further state, "the task that faces the sociologist of the community is to generalize, whilst avoiding normative prescription, from the basis of empirical descriptions based on a myriad of theoretical positions which vary enormously in their explicitness. The studies themselves are too often incomplete descriptions of the locality because the 'problem' or the 
'theory' dictated that only certain areas were investigated. This is an enormously difficult and challenging task" (1971, p. 252).

24. It must be added that whenever Tönnies addressed the purpose of communal social norms, he tended to employ historically narrow ideologies. In his view, the patriarchal form of community is the necessary consequence of evolution and is thus, by implication, the general and most natural form of community. In truth, however, this is not a mandatory result of the anthropological process but rather plays into the common myth of community as a patriarchal system. It may be the uncritical acceptance of such historical prejudices that motivated numerous political groups after the 1920s to use Tönnies' work to legitimise their conservative ideologies of community (Walther 1991).

25. It also must be noted here that care at a distance, whether physical, geographical, emotional or technological, need not result in less intensive care for patients or residents. In Care at a Distance: On the Closeness of Technology, for instance, Jeannette Pols (2012) persuasively demonstrates by drawing on ethnographic observations of both carers and patients involved in telecare, that there is a rise in the frequency of contact between the two.

\section{References}

Ballard, C., \& Bannister, C. (2010). Criteria for the Diagnosis of Dementia. In J. O’Brian, D. Amesn, \& A. Burns (Eds.), Dementia (pp. 31-47). London: Martin Dunitz.

BBC. (2014). Suffolk Replica Village Boosts Dementia Patient Memories. Bbc. co.uk. Retrieved March 3, 2016, from http://www.bbc.co.uk/news/ uk-england-suffolk-28061574

Bell, C., \& Newby, H. (1971). Community Studies: An Introduction to the Sociology of the Local Community. London: Allen and Unwin.

Berry, L. (2013). Lessons from Abroad. Nursing Older People, 25(6), 3. Brenkert, G. G. (1983). Marx's Ethics of Freedom. Oxon: Routledge.

Cahnman, W. J. (1973). Ferdinand Tönnies: A New Evaluation. Leiden: E.J. Brill. Carpenter, J. (2012). Inside Dementiaville. Express.co.uk. Retrieved January 31, 2016, from http://www.express.co.uk/news/retirement/299377/InsideDementiaville

Curren Hamm, A., \& Browning, R. (1942). Robert Browning's Pied Piper of Hamelin. London: Tower Press. 
Durkheim, E. (1951 [1897]). Suicide. Glencoe: Free Press.

Focus. (2012). Die Besten Pflegeheime. FOCUS-Spezial - Wohnen \& Leben im Alter, 11/12, 56-61.

Foucault, M. (1980). Power/Knowledge: Selected Interviews and Other Writings, 1972-1977. Brighton: Harvester Press.

Foucault, M. (1989 [1963]). The Birth of the Clinic_An Archaeology of Medical Perception. Abingdon: Routledge.

Franklin, S., \& Roberts, C. (2006). Born and Made: An Ethnography of Preimplantation Genetic Diagnosis. Oxford: Princeton University Press.

George, D. R. (2010). The Art of Medicine Overcoming the Social Death of Dementia Through Language. The Lancet, 376, 586-587.

Goffman, E. (1961). Asylums: Essays on the Social Situation of Mental Patients and Other Inmates. New York: Anchor Books.

Grogg, R. (2014). Für das Demenzdorf wird geübt. Bernerzeitung.ch. Retrieved March 3, 2016, from http://www.bernerzeitung.ch/region/emmental/Fuerdas-Demenzdorf-wird-geuebt/story/14390483

Grün, O. (1998). Zukünftige Organisationsstrukturen für Alters- und Pflegeheime. Zeitschrift für Gerontologie und Geriatrie, 31(6), 398-406.

Gubrium, J. (1986). Oldtimers and Alzheimer's: The Descriptive Organization of Senility. London: JAI Press Inc.

Haeusermann, T. (2017). The Dementias-A Review and a Call for a Disaggregated Approach. Journal of Aging Studies, 42, 22-31.

Henley, J. (2012). The Village Where People Have Dementia-And Fun. Theguardian.com. Retrieved March 3, 2016, from http://www.theguardian. com/society/2012/aug/27/dementia-village-residents-have-fun

Hogewoning-van der Vossen, A. (2004). Living in Lifestyle Groups in Nursing Home-Changeover to a Psychosocial Model of Care-Giving in Dementia. In G. N. M. Jones \& B. M. L. Miesen (Eds.), Care-Giving in Dementia: Research and Applications (pp. 97-122). Hove: Brunner-Routledge.

Hurley, D. (2012). "Village of the Demented" Draws Praise as New Care Model. Neurology Today, 12(10), 12-13.

Ivry, T. (2010). Embodying Culture: Pregnancy in Japan and Israel. New Brunswick: Rutgers University Press.

Jacobson, D. (1991). Reading Ethnography. New York: State University of New York Press.

Jenkins, C., \& Smythe, A. (2013). Reflections on a Visit to a Dementia Care Village. Nursing Older People, 25, 14-19.

Jugendanstalt Hameln. (2015). Herzlich Willkommen auf der Homepage der Jugendanstalt Hameln. Retrieved March 3, 2016, from http://www. 
jugendanstalt-hameln.niedersachsen.de/portal/live.php?navigation_ id $=24052 \& \_$psmand $=180$

Kalish, R. A. (1966). A Continuum of Subjectively Perceived Death. The Gerontologist, 6(2), 73-76.

Keller, A. (2013). Demenzdorf Alzey in der Prüfung: Ist das Modell ein Pflegeheim? News.wohnen-im-alter.de. Retrieved March 3, 2016, from http:// news.wohnen-im-alter.de/2013/07/demenzdorf-alzey-in-der-prufung-istdas-modell-ein-pflegeheim/

Keller, A. (2014). Tönebön am See: Erstes „Demenzdorf“ Deutschlands in Hameln eröffnet. News.wohnen-im-alter.de. Retrieved March 3, 2016, from http://news.wohnen-im-alter.de/2014/04/erstes-demenzdorf-deutschlandshameln-eroeffnet/

Kleinman, A. (1988). The Illness Narratives - Suffering, Healing, and the Human Condition. New York: Basic Books.

Kübler-Ross, E. (1969). On Death and Dying. London: Routledge.

Lawson, W. (2008). Concepts of Normality: The Autistic and Typical Spectrum. London: Jessica Kingsley Publishers.

Lock, M. (1993). Encounters with Aging: Mythologies of Menopause in Japan and North America. London: University of California Press.

Lock, M. (2013). The Alzheimer Conundrum: Entanglements of Dementia and Aging. Woodstock: Princeton University Press.

Marcus, J. E., \& Cushman, P. (1982). Ethnographies as Texts. Annual Review of Anthropology, 11, 25-69.

Melville, K. (1972). Communes in the Counter Culture: Origins, Theories, Styles of Life. New York: William Morrow and Company.

Merz-Benz, P-U. (1991). Die begriffliche Architektonik von „Gemeinschaft und Gesellschaft“. In L. Clausen \& C. Schlüter (Eds.), Hundert Jahre "Gemeinschaft und Gesellschaft". Ferdinand Tönnies in der internationalen Diskussion (pp. 31-64). Opladen: Leske+Budrich.

Noddings, N. (1984). Caring: A Feminine Approach to Ethics and Moral Education. London: University of California Press.

Paterson, T. (2012). Switzerland's "Dementiaville” Designed to Mirror the Past. Independent.co.uk. Retrieved March 3, 2016, from http://www.independent. co.uk/news/world/europe/switzerlands-dementiaville-designed-tomirrorthe-past-6293712.html

Pickering, M. (2009). Auguste Comte: Volume 3: An Intellectual Biography. Cambridge: Cambridge University Press.

Pols, J. (2012). Care at a Distance. Amsterdam: Amsterdam University Press.

Rosenhan, D. (1973). On Being Sane in Insane Places. Science, 179(4070), 250-258. 
Smith, D. E. (1974). The Social Construction of Documentary Reality. Sociological Inquiry, 44(4), 257-268.

Tagliabue, J. (2012). Taking on Dementia with the Experiences of Normal Life. Nytimes.com. Retrieved March 3 2016, from http://www.nytimes. com/2012/04/25/world/europe/netherlands-hogewey-offers-normal-life-todementia-patients.html?_r=0

Tönebön Stiftung. (2016). Tönebön Stiftung-Ihr Partner Im Alter. toeneboenstiftung.de. Retrieved March 3, 2016, from http://www.toeneboen-stiftung. de/

Tönnies, F. (2001 [1887]). Tönnies: Community and Civil Society (J. Harris \& M. Hollis, Trans.). Cambridge: Cambridge University Press.

Townsend, P. (1952). The Purpose of the Institution. In C. Tibbits \& W. Donahue (Eds.), Social and Psychological Aspects of Aging (pp. 378-399). New York: Columbia University Press.

Vivium Zorggroep. (2016). Verpleeghuis Hogewey. vivium.nl. Retrieved March 3, 2016, from www.vivium.nl/hogewey

Walther, M. (1991). Gemeinschaft und Gesellschaft bei Ferdinand Tönnies und in der Sozialphilosophie des 17. Jahrhunderts oder: Von Althusius über Hobbes zu Spinoza-und zurück. In L. Clausen \& C. Schlüter (Eds.), Hundert Jahre »Gemeinschaft und Gesellschaft«. Ferdinand Tönnies in der internationalen Diskussion (pp. 83-106). Opladen: Leske+Budrich.

Weinberg, D. (2005). Of Others Inside: Insanity, Addiction, and Belonging in America. Philadelphia: Temple University Press.

Weiner, M. F., \& Lipton, A. M. (2009). The American Psychiatric Publishing Textbook of Alzheimer's Disease and Other Dementias. Arlington: American Psychiatric Publishing.

Zola, I. K. (1972). Medicine as an Institution of Social Control. The Sociological Review, 20, 487-504.

Open Access This chapter is licensed under the terms of the Creative Commons Attribution 4.0 International License (http://creativecommons.org/licenses/ by/4.0/), which permits use, sharing, adaptation, distribution and reproduction in any medium or format, as long as you give appropriate credit to the original author(s) and the source, provide a link to the Creative Commons license and indicate if changes were made. 
The images or other third party material in this chapter are included in the chapter's Creative Commons license, unless indicated otherwise in a credit line to the material. If material is not included in the chapter's Creative Commons license and your intended use is not permitted by statutory regulation or exceeds the permitted use, you will need to obtain permission directly from the copyright holder.

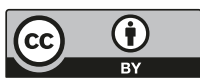

